\title{
On-board Breeding Trial of Hilsa (Tenualosa ilisha, Ham. 1822) and Testing of Larval Rearing in Bangladesh
}

Md. Anisur Rahman ${ }^{1}$, Tayfa Ahmed ${ }^{1}$, Md. Mehedi Hasan Pramanik ${ }^{1}$, Flura ${ }^{1}$, Md. Monjurul Hasan ${ }^{1 *}$, M. G. S. Riar ${ }^{2}$, Khandaker Rashidul Hasan ${ }^{3}$, Masud Hossain Khan ${ }^{1}$ and Yahia Mahmud ${ }^{4}$

${ }^{1}$ Bangladesh Fisheries Research Institute, Riverine Station, Chandpur, Bangladesh

${ }^{2}$ Bangladesh Fisheries Research Institute, Freshwater Station, Mymensingh, Bangladesh

${ }^{3}$ Bangladesh Fisheries Research Institute, Freshwater Sub-station, Saidpur, Nilphamari, Bangladesh

${ }^{4}$ Bangladesh Fisheries Research Institute, Headquarter, Mymensingh, Bangladesh

\begin{abstract}
The Hilsa shad, Tenualosa ilisha commonly known as Hilsa is one of the most commercially important fish species in South Asian countries. For the conservation of Hilsa it is necessary to establish a standard breeding and culture protocol along with the present Hilsa management activities. The on board breeding trial was conducted during 10 October 2016 to 02 November 2016 which was the peak breeding time of Hilsa for the year 2016 . The male and female Hilsa broods were collected from the River Meghna using BFRI experimental net during afternoon and late evening of full moon and new moon time. A total of six breeding trials were conducted in which 13 pairs of selected Hilsa broods were used for the breeding trials. For the breeding trial, both eggs and milt were collected through stripping and then the eggs were mixed with the milt immediately. The fertilized eggs were transferred to a plastic hatching jar for incubation providing mild water circulation, aeration and shade to protect penetration of direct sunlight for controlling temperature i.e., to maintain congenial environment. During the incubation period, the eggs were observed for $24 \mathrm{hrs}$ to study the embryonic and larval development stages of Hilsa. After 4.2-4.5 hrs of fertilization morula stage of embryonic development was identified and after 8-8.5 hrs. of fertilization 18-myotome stage of embryonic development was identified from the sixth breeding trial. After that, no embryonic development of egg was observed up to $12 \mathrm{hrs}$ after fertilization and the fertilized eggs were found to be dead filled with fungus at the end. The water quality parameters were found in good range during the breeding trial though the temperature was found to be fluctuated from the optimum ranges needed for the incubation of fertilized eggs. Although it was not possible to be succeeded completely in artificial breeding of Hilsa, the experience of on board breeding trial in the major breeding ground of River Meghna will give the necessary insight for future works.
\end{abstract}

Keywords: Tenualosa ilisha; Breeding; Hilsa; Embryonic development; Meghna river; Bangladesh

\section{Introduction}

Hilsa (Tenualosa ilisha, Hamilton) is the most important single species fishery in Bangladesh. It is the most popular food fish to the people of Bay of Bengal region. It is the national fish of Bangladesh which contributes about $11 \%$ of total fish production and $1 \%$ to the GDP [1]. Due to over exploitation and indiscriminate killing of Hilsa from inland open waters specially from the nursery, feeding and breeding ground of Hilsa (Meghna estuary), the fishery was declining very sharply since the year 2000-2001. Number of factors is responsible for this declines including: (i) barrier to natural migration for breeding due to the sedimentation in rivers (ii) excessive fishing pressure at different life stages (iii) river water pollution altering the physicochemical parameters of rivers (iv) habitat destruction [2]. As a result, to conserve Hilsa fishery it was then needed to implement the Hilsa Fishery Management Action Plan (HFMAP), which has ceased the decreasing trends of Hilsa production since 2004 to till date. Although, production of Hilsa has increased in recent years but yet unable to meet the high demand to the first growing population of the country. Farm production of market size Hilsa through Hilsa aquaculture using hatchery seed will be a management measure to increase Hilsa production. Furthermore, growing production rate of fishes (e.g. carps, pangas, shrimps etc.) through pond culture and getting the 4th position throughout the world [3], yet Hilsa culture has not been commercially started in this country due to its typical life pattern. To overcome these limitations, on board breeding trial of Hilsa was introduced as one of the most important management and conservation measures to improve its fishery resources in this region.

\section{Why on board breeding?}

The life cycle of Hilsa is very typical and for that reason artificial breeding outside its natural environment is almost impossible. Hilsa spawn in freshwater and deposit eggs diversely [4]. After spawning, when the larvae can swim, they try to find suitable nursery grounds, normally in the lower region of the rivers in coastal waters and become Jatka i.e., juveniles of Hilsa [5]. The jatka remain around the nursery grounds for about 5-6 months and attain a minimum size of $15-16 \mathrm{~cm}$ $[6,7]$. Generally, the jatka acquire the ability to tolerate saline water and move downstream to the estuary. There, they spend their young life stages in brackish water. Later, the young move offshore for feeding and grow to adult size. After maturation, the adult again migrates upstream for spawning following the same life pattern. As a result, for successful aquaculture, the life cycle of Hilsa will be necessary to take into account. For on-board breeding trial, it is very important to create semi natural environment. If finally, it is possible to breed Tenualosa

${ }^{*}$ Corresponding author: Md. Monjurul Hasan, Bangladesh Fisheries Research Institute, Riverine Station, Chandpur, Bangladesh, Tel: +880-1751840077; E-mail: mhshihab.hasan@gmail.com

Received February 22, 2016; Accepted March 29, 2017; Published March 31, 2017

Citation: Rahman MA, Ahmed T, Pramanik MMH, Flura, Hasan MM, et al (2017) On-board Breeding Trial of Hilsa (Tenualosa ilisha, Ham. 1822) and Testing of Larval Rearing in Bangladesh. J Aquac Res Development 8: 471. doi: 10.4172/2155-9546.1000471

Copyright: () 2017 Rahman MA, et al. This is an open-access article distributed under the terms of the Creative Commons Attribution License, which permits unrestricted use, distribution, and reproduction in any medium, provided the original author and source are credited. 
Citation: Rahman MA, Ahmed T, Pramanik MMH, Flura, Hasan MM, et al. (2017) On-board Breeding Trial of Hilsa (Tenualosa ilisha, Ham. 1822) and Testing of Larval Rearing in Bangladesh. J Aquac Res Development 8: 471. doi: 10.4172/2155-9546.1000471

Page 2 of 8
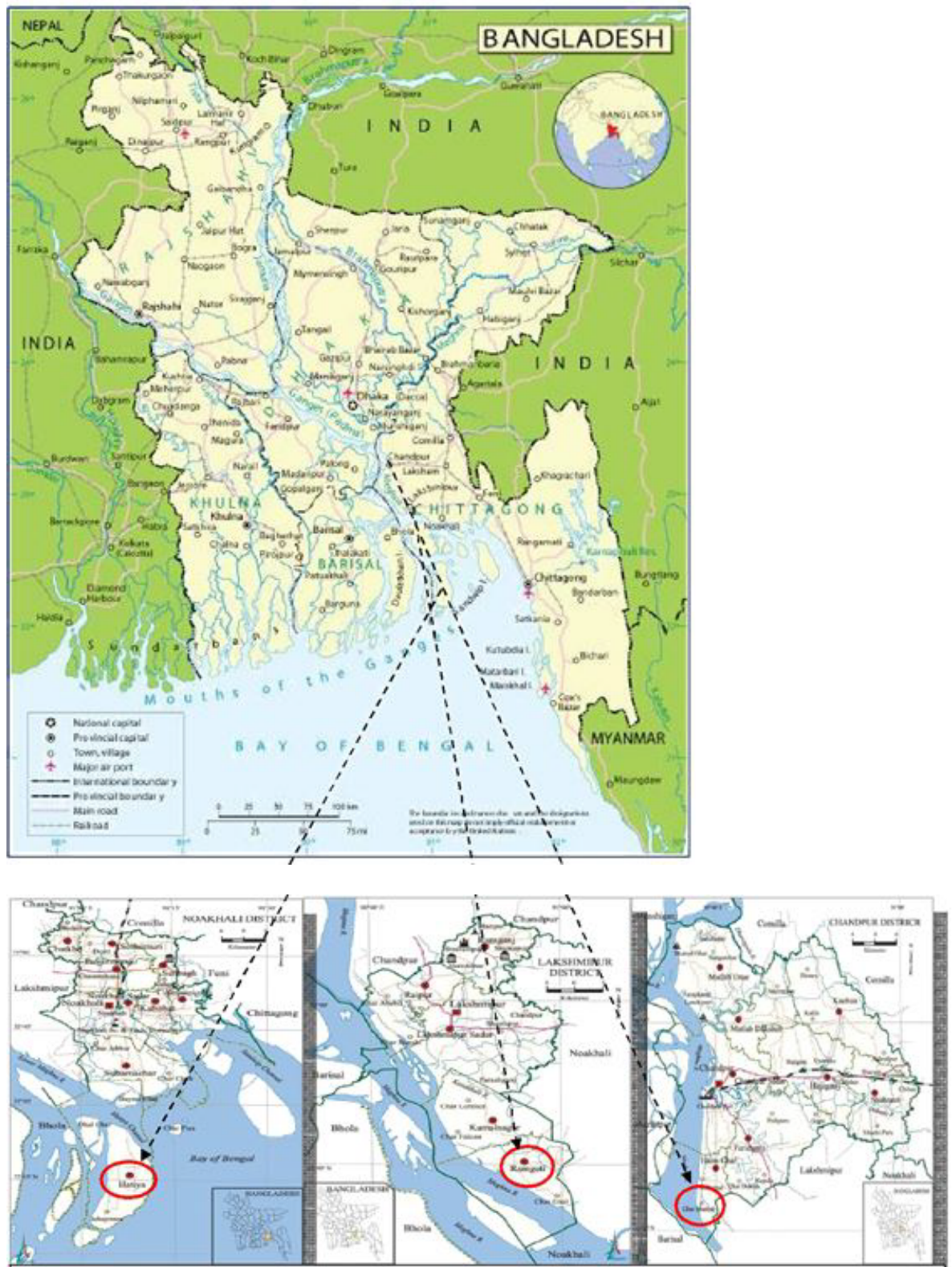

Figure 1: Map showing sampling spots in the Meghna river for collecting matured gravid Hilsa.

ilisha like Tenualosa toli in Malaysia, then that would open a new window for Hilsa aquaculture in confined water.

\section{Previous year's achievements}

The first on-board breeding trial was conducted by the Riverine Station (RS) Hilsa Research Team of Bangladesh Fisheries Research Institute (BFRI) in the major breeding grounds of Hilsa at the River Meghna of Bangladesh during the period of 25 September 2015 to 09 October 2015. About 11 pairs of brood Hilsa were collected from the River Meghna using gill net in the afternoon and late evening. From the collected broods 08 pairs were tried for breeding by direct stripping and 03 pairs were tried by dopamine injection for artificial breeding. The collected eggs were fertilized by the milt immediately. The fertilized eggs were observed for $24 \mathrm{hrs}$ to study the embryonic and larval development stages of Hilsa. After $6 \mathrm{hrs}$ some fertilized eggs were found to be denatured and $24 \mathrm{hrs} \mathrm{later}$ all the fertilized eggs were found to be dead. The water quality parameters were found to be in good range during the breeding trial of Hilsa [8].

\section{Material and Methods}

\section{Timeframe selection}

Breeding trial activities were carried out between 10 October to 2 November 2016 in the River Meghna of Bangladesh. A total of six breeding trials were completed by the Riverine Station (RS) Hilsa Research Team of Bangladesh Fisheries Research Institute (BFRI) with speed boat \& research vessel M. V. Rupali Ilish.

The matured/adult Hilsa ( $1^{+}$age group) congregates in the major spawning grounds of Hilsa in lower Meghna estuaries for spawning. However, Hilsa spawn year-round but considerably two times in a year, 


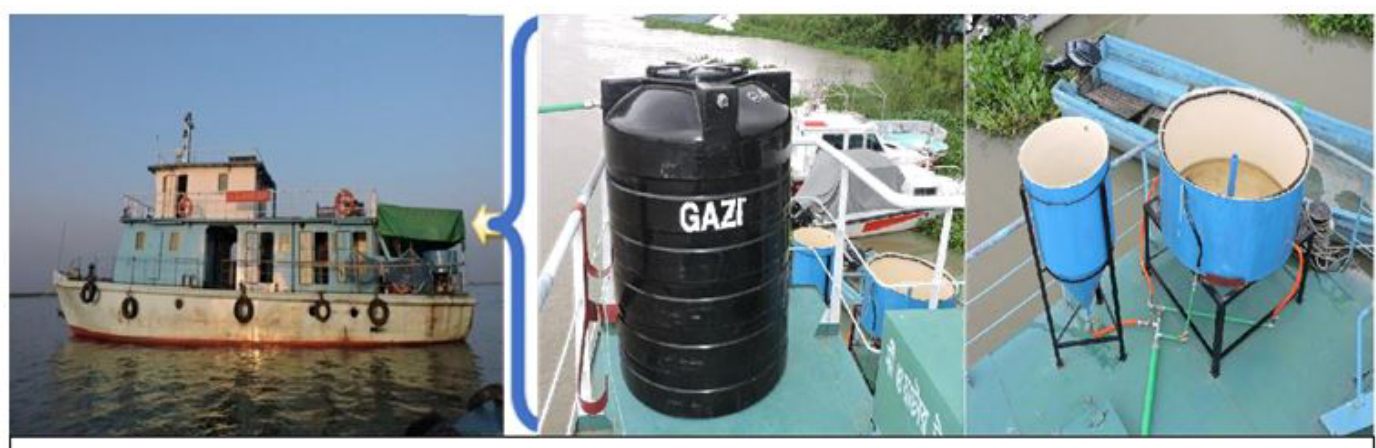

Figure 2: Pictorial view of reserve tank, bottle hatchery and circular tank set up on research vessel for on-board breeding trial of Hilsa

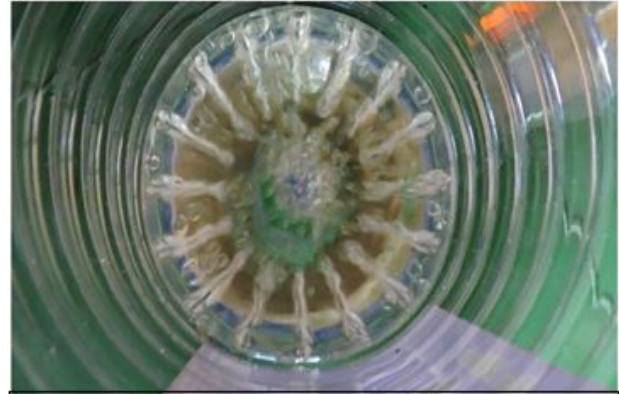

Figure 3: Aeration in hatching bottle.

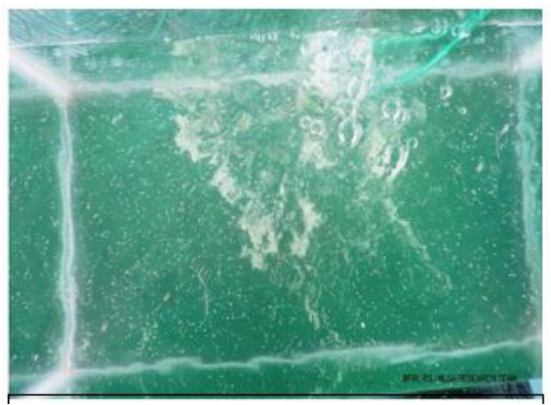

Figure 4: Aeration in hatching jar.

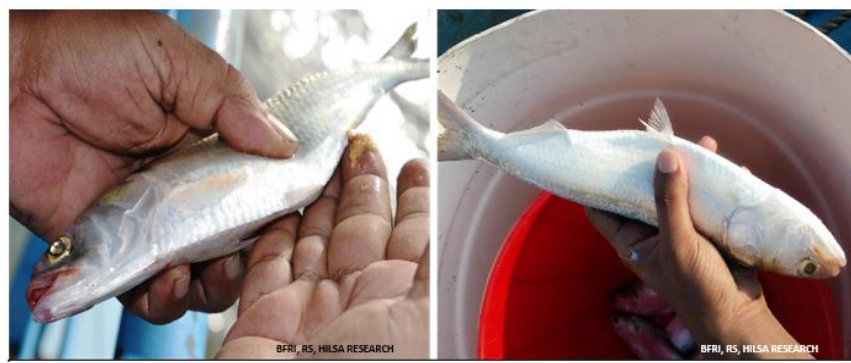

Figure 5: Sorting of matured female and male Hilsa suitable for breeding trial.

which are the 1st peak-spawning season (September-October) and in the $2^{\text {nd }}$ peakspawning season (January-March). This was the major reason of selecting this time period for the conduction of on-board breeding trials.

\section{Spot selection for artificial breeding}

On the basis of availability of matured Hilsa, three sampling spots were identified by the Riverine Station (RS) Hilsa Research Team of Bangladesh Fisheries Research Institute (BFRI) (Figure 1):
a) Chairman ghat and Hatia (Noakhali)
b) Ramgoti (Laxmipur)
c) Katakhal and Charvoirobi (Chandpur)

\section{Breeding protocol fix up}

Breeding protocol has been made and standardized from the previous breeding trial experiences done by Riverine Station (RS) Hilsa Research Team of Bangladesh Fisheries Research Institute (BFRI) and from literature as well.

\section{Preparation of breeding equipment's}

Breeding equipment's such as bottle hatchery, circular tank, overhead tank, hatching jar and all other breeding apparatus were used for breeding operation. A portable model hatchery was established on the research vessel by M.V. Rupali Ilish to provide the breeders to breed in semi-natural condition. The portable hatchery, which was set up on the research vessel for on board breeding trial consists of four units (Figure 2) - a) Overhead tank b) Circular tank c) Bottle hatchery and d) Hatching jar.

Overhead tank: A plastic overhead tank of 1000 litres capacity was placed at 3.5-meter-high above the other operational hatchery unit's setup on the ground floor of the research vessel. River water of spawning grounds was stored in the overhead tank for the hatchery operation.

Circular tank: An iron sheet made circular tank of 500-liter capacity was setup on the ground floor of the research vessel. The collected broods were stocked in this tank for artificial breeding providing water supply, oxygenation, and disinfectant into the water.

Bottle hatchery: A 100 litre capacity incubation bottle was made (covered and surrounded by zero mesh sized net) for incubation of fertilized eggs. A fry-collecting outlet was also connected with the jar. The incubation jar was setup on the ground floor of the research vessel providing water supply with mild circulation and mild oxygenation by flow (Figure 3).

Hatching jar: A 3 litre capacity plastic jar with air stone was also used for the hatching of eggs (Figure 4). A 15-litre capacity sized plastic 
Citation: Rahman MA, Ahmed T, Pramanik MMH, Flura, Hasan MM, et al. (2017) On-board Breeding Trial of Hilsa (Tenualosa ilisha, Ham. 1822) and Testing of Larval Rearing in Bangladesh. J Aquac Res Development 8: 471. doi: 10.4172/2155-9546.1000471

Page 4 of 8

\begin{tabular}{|c|c|c|c|c|c|c|c|c|c|c|}
\hline \multirow{2}{*}{ Trial No. } & \multirow{2}{*}{ Location } & \multicolumn{2}{|c|}{ Brood Hilsa pair No. } & \multicolumn{2}{|c|}{ Length Range $(\mathrm{cm})$} & \multicolumn{2}{|c|}{ Weight Range (g) } & \multirow{2}{*}{$\begin{array}{l}\text { Stripping } \\
\text { Time (hr) }\end{array}$} & \multirow{2}{*}{ Date } & \multirow{2}{*}{ Moon Phase } \\
\hline & & Male & Female & Male & Female & Male & Female & & & \\
\hline $1 \mathrm{st}$ & Katakhali, Chandpur & 2 & 4 & $26.5-34$ & $26-35$ & $250-510$ & $220-370$ & $12: 30$ & $13-10-2016$ & $1^{\text {st }}$ Quarter +4 days \\
\hline $2 n d$ & $\begin{array}{l}\text { Ramgoti,Laxmipur and } \\
\text { chairman ghat, Noakhali }\end{array}$ & 2 & 2 & $31-33$ & $36-37$ & $230-364$ & $550-568$ & $15: 15$ & $15-10-2016$ & $\begin{array}{l}\text { Previous day of } \\
\text { Full Moon }\end{array}$ \\
\hline $3 r d$ & Moulavir Char, Hatia, Noakhali & 2 & 1 & $26-26.5$ & 31 & $174-196$ & 266 & $19: 15$ & $20-10-2016$ & Full Moon+4 days \\
\hline 4th & Katakhali, Chandpur & 3 & 1 & $28-34.5$ & 25.5 & $190-452$ & 162 & $16: 30$ & $29-10-2016$ & $\begin{array}{l}\text { Previous day of } \\
\text { New Moon }\end{array}$ \\
\hline 5 th & Charvoirobi, Chandpur & 4 & 2 & $27-28$ & $26-32$ & $192-298$ & $142-363$ & $17: 00$ & $1-11-2016$ & New Moon+1 day \\
\hline 6th & Katakhali, Chandpur & 2 & 1 & $24-26$ & 33 & $136-148$ & 398 & $17: 05$ & $1-11-2016$ & New Moon+1 day \\
\hline
\end{tabular}

Table 1: Location wise breeding trials of Hilsa broods with different length and weight ranges.

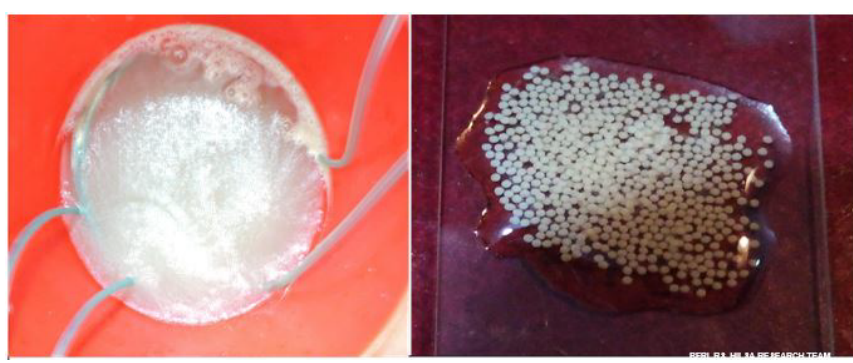

Figure 6: Pictorial view of fertilized Hilsa eggs and aeration of fertilized Hilsa eggs.

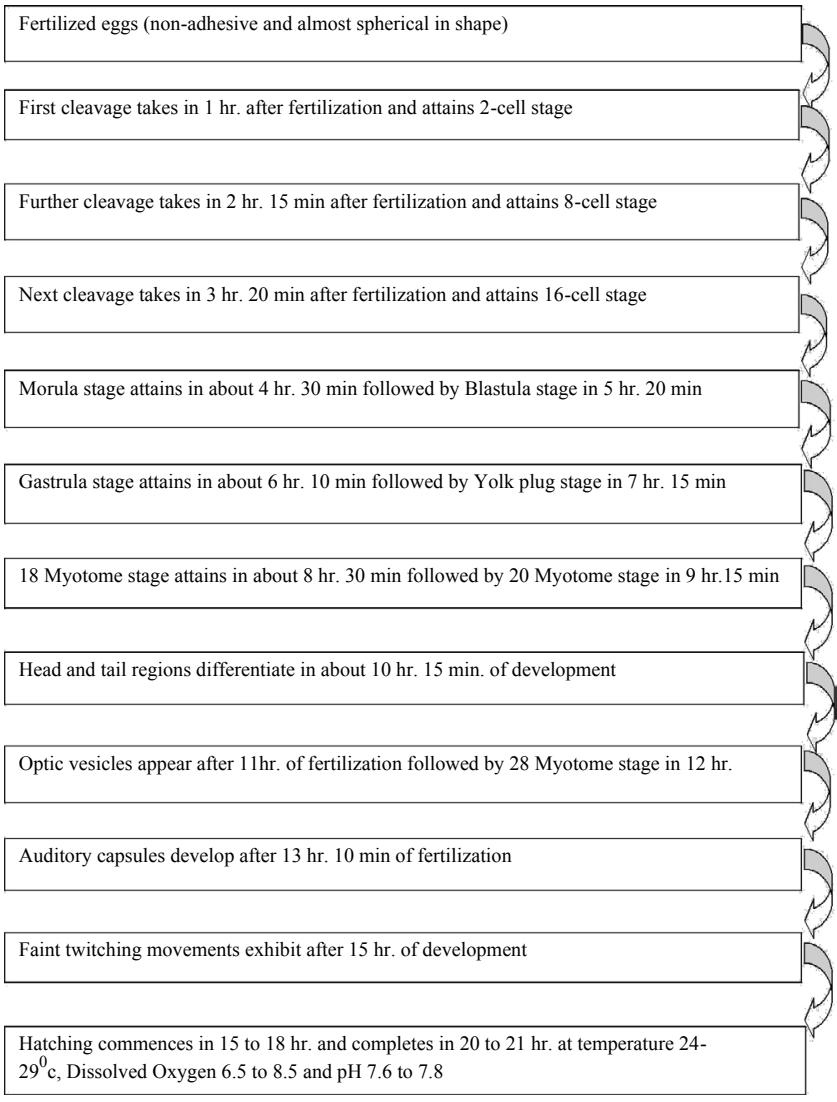

Figure 7: Flow diagram of Hilsa breeding protocol (Modified by BFRI, RS, Hilsa Research Team). bowl was used for the collection of spawn/fry provided with aeration when needed.

\section{BFRI Experimental Net operation for collecting suitable gravid Hilsa}

For breeding experiment, BFRI Experimental Net was successfully operated and suitable gravid Hilsa were collected. BFRI Experimental Net is a $6.5 \mathrm{~cm}$ to $7.5 \mathrm{~cm}$ mesh sized gill net (multidimensional net).

\section{Conditioning}

After collection, selected matured broods were sorted (Figure 5) and kept in a bowl full of river water of spawning grounds for conditioning. To ready the fish for egg release, natural environmental condition was maintained by providing water circulation and oxygenation.

\section{Breeding Process/framework}

The whole breeding process was as follows

Live fish stripping: Altogether a total of 13 pairs of brood Hilsa (Table 1) with different length and weight ranges were tried for breeding collected from the major spawning grounds of Hilsa during the ban period. These breeding trials were done depending upon the collection of fully matured Hilsa broods.

Egg and Milt collection and mixing: Eggs from the matured female and milt from the matured male were collected through stripping and then mixed with the caudal fin of Hilsa.

Releasing of mixed solution (Egg and Milt) in plastic hatching jar: After that fertilized eggs were transferred to a plastic hatching jar for incubation providing mild water circulation, aeration and shade to protect the penetration of direct sunlight (which increase the water temperature also) as this species is light sensitive.

Temperature controlling: Temperature was controlled by restricting the open sunlight from the incubation jar. The incubation jar was also covered with black wet cloth.

Observation of fertilized eggs and embryonic development stages: Embryonic development stages of fertilized eggs were observed under compound microscope continuously until the dead cell was found (Figure 6).

\section{Crosscheck for ensuring the embryonic developmental stages}

Embryonic development stages of fertilized eggs were identified and crosschecked followed by observations on the embryonic and early larval development of Indian shad, Tenualosa ilisha [9] 
Citation: Rahman MA, Ahmed T, Pramanik MMH, Flura, Hasan MM, et al. (2017) On-board Breeding Trial of Hilsa (Tenualosa ilisha, Ham. 1822) and Testing of Larval Rearing in Bangladesh. J Aquac Res Development 8: 471. doi: 10.4172/2155-9546.1000471

Page 5 of 8

\section{Water quality observation}

Important physico-chemical parameters viz. air temperature, water temperature, $\mathrm{pH}$, Dissolved Oxygen, free Carbon dioxide and alkalinity and hardness of breeding grounds and reserved water of portable model hatchery were also observed during the period of breeding trial.

\section{Results}

\section{Finalized breeding protocol}

The breeding protocol was modified and finalized following $[9,10]$ (Figure 7)

\section{Collection and sorting of matured gravid Hilsa}

A total of 259 gravid Hilsa were collected during the whole breeding operation. Most of the female broods were found to be matured and

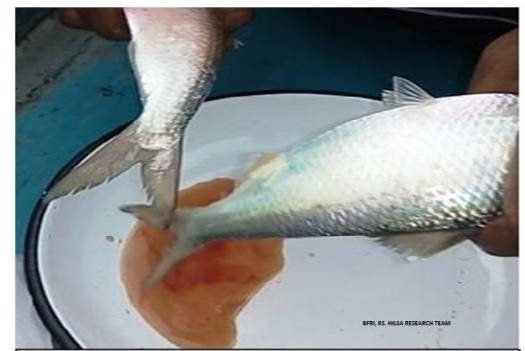

Figure 8: Mixing of eggs and milt collected from the female and male Hilsa broods through stripping.

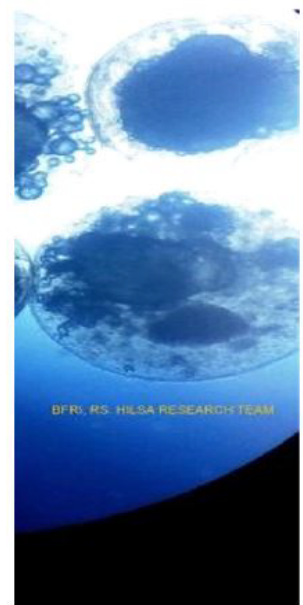

Figure 9: Dead fertilized egg cell of Hilsa.

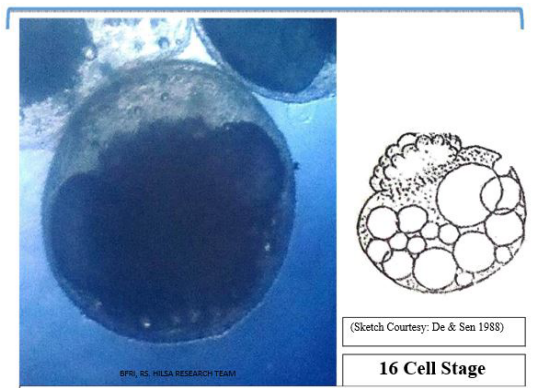

Figure 10: Sixteen (16)-cell stage of embryonic development of Hilsa egg their maturity stages were found between $\mathrm{V}$ to $\mathrm{VI}^{+}$. Large transparent ova that ooze out at the slightest pressure were marked stage $\mathrm{VI}^{+}$as maturity stage in female Hilsa. Vas deferens full of milt which oozes out freely through little pressure were marked stage $\mathrm{VI}^{+}$as maturity stage in male Hilsa.

\section{Breeding trial}

Breeding trials were completed at the time of ban period of Hilsa catching in Bangladesh at different locations following breeding protocols.

\section{Mixing of eggs and milt}

Immediately after getting the oozing female, the eggs were stripped into a bowl by wet method and the milt from the males were also stripped over the eggs for fertilization. Then the eggs and milt were mixed by the caudal fin of Hilsa gently (Figure 8).

\section{Observation of fertilized eggs and embryonic developmental stages}

A total of 6 breeding trials were conducted at the time of ban period of Hilsa catching at different locations.

First breeding trial: First breeding trial was conducted at Katakhal, Chandpur on 13 October 2016 where 2 males and 4 female Hilsa broods were utilized. Collected eggs and milt through stripping were mixed and released in the incubation jar provided with good water circulation and oxygenation. The eggs were fertilized; vitelline membrane and cytoplasmic membrane formed around the egg yolk. Immediately after the fertilization of eggs, these started swelling. The eggs were found very soft, smooth, non-adhesive and almost spherical in shape. After 1-1.2 hrs of fertilization vitelline membrane were found to be separated from the egg yolk and cleavage occurred which were observed under the electron (compound) microscope. This stage was identified as 2-cell stage of embryonic development. Then further cleavage was observed after 2.3-3 hrs of fertilization. This stage was identified as 8-cell stage of embryonic development. After that, no embryonic development was observed up to 6-7 hrs after fertilization and after that eggs were found dead (Figure 9).

Second breeding trial: Another breeding trial was operated at Ramgoti, Laxmipur and Chairman ghat, Noakhali on 15 October 2016 where 2 males and 2 female Hilsa broods were utilized. Collected eggs and milt through stripping were mixed and released in the incubation jar provided with good water circulation and oxygenation. No fertilized eggs were found under electron (compound) microscope which could be due to the less maturity of Hilsa broods.

Third breeding trial: The next breeding trial was conducted at Moulavir char, Hatia on 20 October 2016 where 2 males and 1 female Hilsa broods were utilized. Collected eggs and milt through stripping were mixed and released in the incubation jar provided with good water circulation and oxygenation. The eggs were fertilized; vitelline membrane and cytoplasmic membrane formed around the egg yolk. Immediately after the fertilization of eggs, these started swelling. The eggs were found very soft, smooth, non-adhesive and almost spherical in shape. After 1-1.3 hrs of fertilization vitelline membrane were found to be separated from the egg-yolk and cleavage occurred which was observed under the electron (compound) microscope. This stage was identified as 2-cell stage of embryonic development. Then further cleavage was observed after 2.3-2.6 hrs of fertilization. This stage was identified as 8-cell stage of embryonic development. After that, no embryonic development was observed up to 6-7 hrs after fertilization. 
Citation: Rahman MA, Ahmed T, Pramanik MMH, Flura, Hasan MM, et al. (2017) On-board Breeding Trial of Hilsa (Tenualosa ilisha, Ham. 1822) and Testing of Larval Rearing in Bangladesh. J Aquac Res Development 8: 471. doi: 10.4172/2155-9546.1000471

Page 6 of 8

Fourth breeding trial: Another breeding trial was operated at Katakhal, Chandpur on 29 October 2016 where 3 male and 1 female Hilsa broods were utilized. Collected eggs and milt through stripping

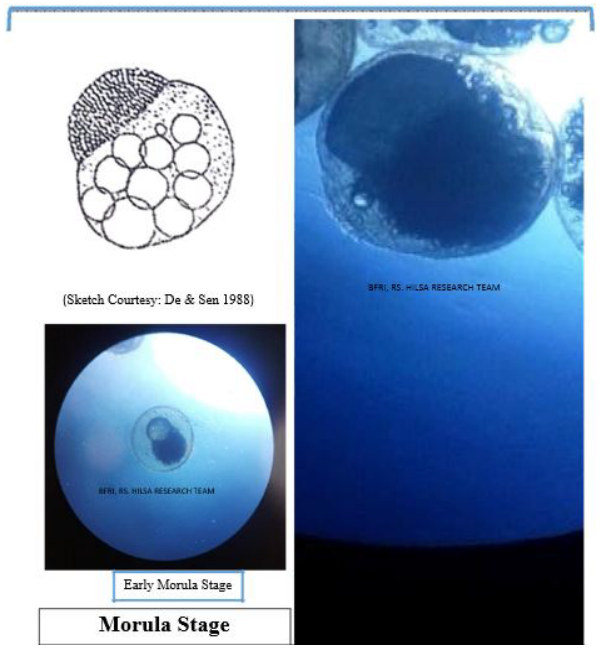

Figure 11: Morula stage of embryonic development of Hilsa egg.

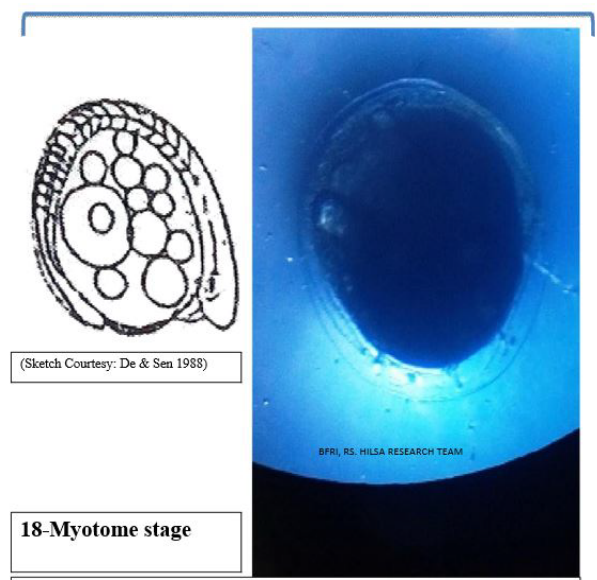

Figure 12: 'Eighteen (18)-Myotome' stage of embryonic development of Hilsa egg.

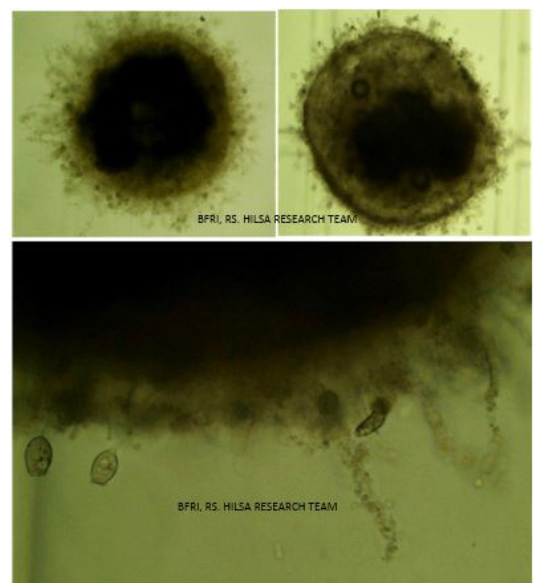

Figure 13: Dead filled 8 to 16 -cell of embryonic development stage of Hilsa egg with fungus. were mixed and released in the incubation jar provided with good water circulation and oxygenation. No fertilized eggs were found under electron (compound) microscope, which could be due to the less maturity of Hilsa broods.

Fifth breeding trial: The 5th breeding trial was conducted at Charvoirobi, Chandpur on 01 November 2016 where 2 males and 4 female Hilsa broods were utilized. Collected eggs and milt through stripping were mixed and released in the incubation jar provided with good water circulation and oxygenation. The eggs were fertilized; vitelline membrane and cytoplasmic membrane formed around the egg yolk. Immediately after the fertilization of eggs, these started swelling. The eggs were found very soft, smooth, non-adhesive and almost spherical in shape. After $3 \mathrm{hrs}$ of fertilization no further embryonic development was observed and the eggs were found to be ruptured which could be due to the collection of less matured Hilsa broods and also may be the water temperature could not be maintained at desired level.

Sixth breeding trial: The final breeding trial was conducted at Katakhal, Chandpur on 01 November 2016 where 2 males and 1 female Hilsa broods were utilized. Collected eggs and milt through stripping were mixed and released in the incubation jar provided with good water circulation and oxygenation. The eggs were fertilized; vitelline membrane and cytoplasmic membrane formed around the egg yolk. Immediately after the fertilization of eggs, these started swelling. The eggs were found very soft, smooth, non-adhesive and almost spherical in shape. After 1.1-1.4 hrs of fertilization vitelline membrane were found to be separated from the egg yolk and cleavage occurred which was observed under the electron (compound) microscope. This stage was identified as 2-cell stage of embryonic development. Then further cleavage was observed after 2.2-2.5 hrs of fertilization. This stage was identified as 8-cell stage of embryonic development. After 3-3.5 hrs of fertilization further cleavage was observed and this stage was identified as 16-cell stage of embryonic development (Figure 10). Then 4.24.5 hrs. of fertilization morula stage of embryonic development was identified (Figure 11). 18-myotome stage of embryonic development was identified after 8-8.5 hrs. of fertilization (Figure 12). After that, no embryonic development of egg was observed up to $12 \mathrm{hrs}$ after fertilization and the eggs were found to be dead filled with fungus at the end (Figure 13)

\section{Water quality monitoring}

Important physico-chemical parameters viz. air temperature; water temperature, $\mathrm{pH}$, Dissolved Oxygen, free Carbon dioxide, alkalinity and hardness of breeding grounds and reserved water of portable model hatchery were also monitored during the breeding trials. Water quality parameters were found very congenial in range (Table 2). It was not possible to maintain the water temperature at desired level.

\section{Discussion}

Hilsa ascends the fresh water stretches of the rivers from coastal areas of sea mainly for breeding $[4,11,12]$. Presently, in almost all river systems of many countries the abundance of the species has drastically dwindled [13]. Many workers [12,14] have suggested the possibilities of Hilsa culture in confined water bodies. There is an urgent need for development of hatchery and grow out technology of Hilsa species due to the great national and international interest as well as enormous commercial interest [13]. Study from [13] revealed that the size of sexual maturity attained by male and female Hilsa vary from $160 \mathrm{~mm}$ to $400 \mathrm{~mm}$ and $190 \mathrm{~mm}$ to $430 \mathrm{~mm}$ respectively. Stages of maturity of female gonads have been studied by few workers [15-17] revealing that female below $300 \mathrm{~mm}$ size group hardly take part in spawning activity. 
Citation: Rahman MA, Ahmed T, Pramanik MMH, Flura, Hasan MM, et al. (2017) On-board Breeding Trial of Hilsa (Tenualosa ilisha, Ham. 1822) and Testing of Larval Rearing in Bangladesh. J Aquac Res Development 8: 471. doi: 10.4172/2155-9546.1000471

Page 7 of 8

\begin{tabular}{|c|c|c|c|c|c|c|c|c|c|c|c|c|}
\hline \multirow{3}{*}{$\begin{array}{l}\text { Location and trial } \\
\text { No. } \\
\text { Breeding Units }\end{array}$} & \multicolumn{2}{|c|}{ Katakhal } & \multicolumn{2}{|c|}{ Ramgoti } & \multicolumn{2}{|c|}{ Moulavir Char } & \multicolumn{2}{|c|}{ Katakhal } & \multicolumn{2}{|c|}{ Charvoirobi } & \multicolumn{2}{|c|}{ Katakhal } \\
\hline & \multicolumn{2}{|c|}{$1^{\text {st }}$ trial } & \multicolumn{2}{|c|}{$2^{\text {nd }}$ trial } & \multicolumn{2}{|c|}{$3^{\text {rd }}$ trial } & \multicolumn{2}{|c|}{$4^{\text {th }}$ trial } & \multicolumn{2}{|c|}{$5^{\text {th }}$ trial } & \multicolumn{2}{|c|}{$6^{\text {th }}$ trial } \\
\hline & BG & $\mathrm{HJ}$ & BG & $\mathrm{HJ}$ & BG & $\mathrm{HJ}$ & BG & $\mathrm{HJ}$ & BG & $\mathrm{HJ}$ & BG & $\mathrm{HJ}$ \\
\hline Air Temp. $\left({ }^{\circ} \mathrm{C}\right)$ & 31 & 30 & 30 & 30 & 29.5 & 29 & 28 & 28 & 29 & 28.5 & 29 & 29 \\
\hline Water Temp. $\left({ }^{\circ} \mathrm{C}\right)$ & 29 & 29 & 29 & 28 & 28 & 28 & 29 & 27 & 27 & 26 & 27 & 27 \\
\hline $\mathrm{pH}$ & 8.0 & 7.4 & 7.25 & 7.0 & 7.5 & 7.0 & 7.75 & 7.5 & 7.5 & 7.5 & 7.5 & 7.5 \\
\hline $\mathrm{DO}(\mathrm{mg} / \mathrm{l})$ & 5.6 & 4.8 & 5.0 & 5.0 & 5.3 & 5.1 & 5.3 & 5.2 & 4.8 & 5.0 & 5.0 & 5.1 \\
\hline $\mathrm{CO}_{2}(\mathrm{mg} / \mathrm{l})$ & 24 & 20 & 20 & 16 & 18 & 12 & 14.2 & 13 & 15 & 16 & 12 & 10 \\
\hline Alkalinity (mg/l) & 80 & 76 & 126 & 112 & 115 & 110 & 65 & 68 & 102 & 93 & 85 & 88 \\
\hline Hardness (mg/l) & 92 & 85 & 111 & 108 & 98 & 92 & 81 & 72 & 69 & 61 & 71 & 64 \\
\hline
\end{tabular}

BG: Breeding Ground; HJ: Hatching Jar

Table 2: Water quality parameters of two breeding units.

The spawning season of Hilsa is noticed during July-August to October-November in all river systems and lagoons i.e., Hoogly [10,12], Ganga [18], Chilka [4], Godavari [15], Padma and Meghna $[19,20]$ but in Hooghly estuary the period of spawning is found to be prolonged and extended up to February and March. While in the river Brahmaputra, the peak spawning of Hilsa was observed from May to July [21]. Few workers [22,23] reported that Hilsa spawn throughout the year in Hooghly while [12] opined that the species spawn intermittently and the fish has two distinct breeding season but the same do not spawn twice during the year [24] reported that Hilsa spawn in rivers and estuaries.

Since 1908, several attempts towards artificial spawning of Hilsa have been made [25-28] but the major breakthrough came during late 70s [29].

The breeding trials were mostly conducted either in the afternoon or in the late evening supported by $[17,30]$ who reported that the most suitable time for fertilization is during afternoon and evening. Immediately after fertilization of the eggs, this starts swelling and the color of the yolk turns to light greenish yellow from its original light yellow reported by Hora [14] which was also observed in the present study. About 15-20 min, after fertilization the eggs become almost colorless and attained a size of $1.95 \mathrm{~mm}$ to $2.10 \mathrm{~mm}$ diameter, the average being $2.02 \mathrm{~mm}$. The eggs were very soft, smooth, non-adhesive and almost spherical in shape. The eggs were almost demersal in nature in still water and easily buoyed up and drifted by slight currents [14]. The yolk is roughly spherical with an average diameter of $0.88 \mathrm{~mm}$ [17].

Hilsa spawn in fresh water and deposited eggs demersally. The eggs hatch after $23-26 \mathrm{hrs}$ at an average temperature of $23^{\circ} \mathrm{C}$ [4]. Detailed embryonic and larval development of the species were studied by many workers $[17,28]$. The rate of cleavage and embryonic development varied with the temperature of the water has been reported by the workers. The incubation period was found to be ranged between 18 $20 \mathrm{hrs}$ at $28.5^{\circ} \mathrm{C}$ [28], $18-20 \mathrm{hrs}$. under $23.5^{\circ} \mathrm{C}$ to $30.0^{\circ} \mathrm{C}$ [31] and 18 $21 \mathrm{hrs}$ under $24.0^{\circ} \mathrm{C}$ to $29.0^{\circ} \mathrm{C}$ [17]. The embryonic and early larval development of Hilsa were studied by $[9,17]$ who stated that morula stage attains in about $3 \mathrm{hrs} 30 \mathrm{~min}$ followed by blastula and then gastrula in $5 \mathrm{hrs} 30 \mathrm{~min}$. They also reported that myotomes appear after $10 \mathrm{hrs}$ and hatching completes 20-21 hrs. of fertilization.

\section{Conclusion}

Hilsa shad (Tenualosa ilisha, Hamilton) is the national fish of Bangladesh having great socioeconomic and nutritional value. Since 2004, Hilsa production from wild fishery has increased significantly in Bangladesh, yet unable to meet the increased demand of Hilsa among common people of the country. Though the implementation of Hilsa Fisheries Management Action plan (HFMAP) [32], awareness building among Hilsa fishers and mass people increased Hilsa production in the wild in Bangladesh but it is an urgent need to find out the alternate sources of Hilsa production like culture in captive or semi captive condition by artificial breeding. For the conservation of Hilsa fisheries both in river and sea, several management activities have already been taken both in country and neighboring countries. For example, Hilsha Fisheries Management Action plan (HFMAP) which was being implemented in Bangladesh territory resulting in huge Hilsa production; trans-boundary management plan which was also discussed among Bangladesh, India, Myanmar under the Bay of Bengal Large Marine Ecosystem (BoBLME) project. In captive condition, it was found that Hilsa has grown up slowly but not attained sexual maturity for induced breeding. Efforts on culture of Hilsa have been attempted in India for many years and in Bangladesh recently. Recent efforts by Bangladesh Fisheries Research Institute (BFRI) in Hilsa larval rearing are encouraging but need fine tuning of the existing protocols. As Hilsa has a typical life cycle and high sensitivity to oxygen depletion in water and sunlight, it is very much challenging to get the full success on artificial breeding of this species. To overcome this problem onboard breeding trial can be an important management measures for artificial breeding to produce mass seed production. Hilsa research team of Bangladesh Fisheries Research Institute (BFRI) has been partially successful in on-board breeding trial of Hilsa and reached 18-myotome stage of embryonic development stage of Hilsa eggs.

\section{Challenges and Learning}

The Hilsa Research Team faced many challenges to overcome during the experimental operations, at the same time many things has been learnt through these works which have been stated below:

1. Collection of alive broods (male and female Hilsa).

2. Availability of fully matured male and female Hilsa broods and also to make available at a time is a big challenge.

3. To keep them alive in captive condition longer.

4. Desired Hilsa fish is available in very remote and wild areas.

5. Milt preservation (like cryo-preservation etc.).

6. Supply of appropriate Dissolved Oxygen (DO) and maintaining optimum temperature throughout the incubation period.

7. Multi-dimensional models/methods need to apply for breeding of Hilsa.

\section{Acknowledgement}

This research work was supported by The United States Agency for International Development (USAID)-funded Enhanced Coastal Fisheries (ECOFISHBD) project of World Fish and the authors are thankful to them. 
Citation: Rahman MA, Ahmed T, Pramanik MMH, Flura, Hasan MM, et al. (2017) On-board Breeding Trial of Hilsa (Tenualosa ilisha, Ham. 1822) and Testing of Larval Rearing in Bangladesh. J Aquac Res Development 8: 471. doi: 10.4172/2155-9546.1000471

\section{References}

1. DoF (2016) National Fish week 2016 Compendium (In Bengali). Department of Fisheries, Ministry of Fisheries and Livestock, Bangladesh.

2. BOBLME (2014) Report of the hilsa fisheries assessment working group meeting, Kolkata, India, BOBLME.

3. FAO (2014) The state of world fisheries and aquaculture. Rome.

4. Jones S, Menon PMG (1951) Observations on the life history of the India Shad Hilsa ilisha (Hamilton). Proc Indian Acad Sci 31: 101-125

5. Haldar GC, Rahman MA (1998) Ecology of Hilsa, Tenualosa ilisha (Hamilton). Proceedings of BFRI/ACIAR/CSIRO Workshop on Hilsa Fisheries Research in Bangladesh Held on 3-4 March 1998 at Bangladesh Agricultural Research Council, Dhaka, Bangladesh. Fisheries Research Institute, BFRI Proceedings Series No. 6:11-19.

6. Raja BTA (1985) A review of the biology and fisheries of Hilsa ilisha in the Bay of Bengal. Bay of Bengal Programme, Marine Fishery Resource Management in the Bay of Bengal.

7. Mazid MA, Islam S (1991) Hilsa fishery development and management. A Report Published by Fisheries Research Institute, Mymensingh, Bangladesh.

8. Rahman MA (2015) Status of conservation and migration of Hilsa in the Meghna River Estuary and its potential of breeding for stock enhancement and aquaculture. ECOFISHBD Project. $1^{\text {st }}$ Year Annual Research Progress Report, BFRI, RS, Chandpur.

9. De DK, Sen PR (1988) Observations on the embryonic and early larva development of Indian shad, Tenualosa ilisha (Ham.). J Inland Fish Society of India 18: 1-12.

10. De DK (1980) Maturity, fecundity and spawning of post-monsoon run of Hilsa. Hilsa ilisha in the upper stretches of the Hoogly estuarine system. J Inland Fish Soc 12: $54-63$

11. Hora SL (1938) A preliminary note on the spawning grounds and bionomics of the so called Indian shad, Hilsa ilisha (Ham.) in the river Ganges. Rec Indian Mus 40: 147-148.

12. Pillay TVR (1958) Biology of the hilsa, Hilsa ilisha (Ham.) of the river Hoogly. Indian Journal of Fisheries 5: 201-257.

13. Sahoo AK, Puvanendran V (2012) Status of Hilsa, Tenualosa llisha (Hma.) Aquaculture In India: A review. Regional Workshop on Hilsa: Potential for Aquaculture. Dhaka, Bangladesh.

14. Hora SL (1940) Dams and the problems of migratory fishes. Current Science 9: 406-407.

15. Pillay SR, Rao KY (1962) Observations on the biology and fishery of the Hilsa ilisha (Ham.) of the river Godavari. Proc Indo Pacific Fish Coun 10: 37-61.

16. Mathur PK (1964) Studies on the maturity and fecundity of the Hilsa, Hilsa ilisha (Ham.) in the upper stretches of the Ganga. Indian Journal of Fisheries 11: 426-448.

17. De DK (1986) Studies on the food and feeding habit of hilsa. Hilsa ilisha (Ham.) of the Hoogly estuarine system and some aspects of its biology. University of Calcutta, India.

18. Nair PV (1958) Seasonal changes in the gonads of Hilsa ilisha (Ham.). Philipp J Sci 255-276.

19. Quddus MMA (1982) Two types of Hilsa ilisha and population biology from Bangladesh water. Doctrol Thesis. The University of Tokyo.

20. Quddus MMA, Shimizu M, Nose Y (1984) Spawning and fecundity of two types of Hilsa ilisha in Bangladesh waters. Ibid 50: 177-181.

21. Rao KY, Pathak SC (1972) A note on the occurrence of spawning of Hilsa ilisha (Ham.) in the river Brahmaputra (Assam). Proc Nat Acad Sci India B 42 231-233.

22. Hora SL, Nair KK (1940) Observations on the bionomics and fishery of the India shad. Hilsa ilisha (Ham.) in Bengal waters. Rec Indian Mus 42: 35-50.

23. Bhanot KK (1973) Observations on the spawning of Hilsa ilisha (Hamilton) in the Hoogly Estuary. J Inland Fish Soc, India 5: 50-54

24. Blaber SJM, Milton DA, Brewer, DT, Salini JP (2001) The shads (Genus Tenualosa) of tropical Asia: An overview of their biology, status and fisheries Proceeding of the international Terubok Conference, Malaysia.

25. Wilson HC (1909) Artificial propagation of Hilsa in the Coleroon. Government of Madras, India.

26. Raj BS (1917) On the habits of the hilsa and their artificial propagation in the Coleroon. J Proc Asiat Scc Bengal 13: 184.

27. Southwell T, Prashad B (1918) On Hilsa investigation in Bengal, Bihar and Orisssa. Bull Dept. Fisheries, Bengal, Bihar and Orissa, India.

28. Kulkarani CV (1950) Breeding habits, eggs and early life history of the India shad Hilsa ilisha (Ham.) in the Narbada River. Proc Nar Insl Sci India 15 I69-J 76.

29. Malhotra JC, Mathur PK, Kamal MY, Chandra R, Desai VR (1969) Successful artificial propagation of Hilsa ilisha (Ham.) near Alahabad. Current Sci 38: $429-430$.

30. Sen PR, De DK, Nath D (1990) Experiments on artificial propagation of hilsa Tenualosa ilisha (Ham.). Indian J Fish 37: 159-162.

31. Malhotra JC, Mathur PK, Kamal MY, Mehrotra SN (1970) Observations on the hatching of fertilized eggs of Hilsa ilisha (Ham.) in confined freshwater. Current Science 39: 538-539.

32. Haldar GC, Islam, MR, Akanda MSI (2004) 'Implementation Strategies of Hilsa Fisheries Conservation and Development Management (in Bengali) Fourth Fisheries Project, Department of Fisheries, Ministry of Fisheries and Livestock, Dhaka. 